\title{
3 Research Square \\ Network Pharmacology Study Reveals the Mechanism of Astragali Radix in Treatment of Diabetic Nephropathy
}

\section{Chongmei Tian}

Shaoxing Hospital of Traditional Chinese Medicine

Jing-bai Chen

Shaoxing Hospital of Traditional Chinese Medicine

Xiang Chen

Shaoxing Hospital of Traditional Chinese Medicine

Dao-zong Xia ( $\square$ worksea123@163.com)

Zhejiang Chinese Medical University

\section{Research}

Keywords: network pharmacology, Astragali Radix, diabetic nephropathy, pharmacological mechanism

Posted Date: July 17th, 2020

DOI: https://doi.org/10.21203/rs.3.rs-42374/v1

License: (c) (i) This work is licensed under a Creative Commons Attribution 4.0 International License. Read Full License 


\section{Abstract \\ Background}

Diabetic nephropathy (DN), a unique complication of diabetes, could contribute to an increase in mortality. In this study, we predicted and proved the molecular pharmacological mechanism concerning the protective effects of Astragali Radix on DN.

\section{Methods}

The same potential target genes from Astragali Radix and DN were analyzed and constructed the protein interaction network. Gene Ontology (GO) and Kyoto Encyclopedia of Genes and Genomes (KEGG) enrichmentrelated major targets and signal pathways were performed. The drug-ingredients-target-disease network was visually built using Cytoscape 3.6.1. The beneficial pharmacological activities of quercetin from Astragali Radix were confirmed by CCK-8 assay, determination of antioxidant parameters and Western blotting analysis.

\section{Results}

There are 12 bioactive components from Astragali Radix and 56 same targets between Astragali Radix and DN. The $\mathrm{GO}$ analysis results showed that the biological processes mainly included protein homodimerization activity. KEGG analysis indicate that the screened targets were most closely linked to the mitogen-activated protein kinase (MAPK) signaling pathway. The drug-ingredients-target-disease network results revealed that the therapeutic effects of Astragali Radix mainly included oxidative stress, inflammatory reaction and apoptosis. During the verification process, quercetin from Astragali Radix could attenuate cytotoxicity, enhance catalase (CAT) and superoxide dismutase (SOD) activities and suppress MAPK signaling pathway.

\section{Conclusions}

In the current study, network pharmacology with experimental analysis predicted and proved the therapeutic function of Astragali Radix by improving antioxidant capacity and suppressing MAPK signaling pathway, these investigations could provide a new perspective for further exploration of Astragali Radix on DN treatment.

\section{Background}

Diabetic nephropathy (DN) is a unique complication of diabetes representing main reason of a significant increase in mortality [1]. It is well known that DN is the most prevalent disease resulting in end-stage renal disease (ESRD), in addition its morbidity is significantly rising worldwide [2]. Moreover, the patients with ESRD often need hemodialysis or kidney transplantation to restore the normal kidney function [3]. At present, the therapies for DN mainly focus on controlling the blood pressure and glycemic, and regulating the renin-angiotensin system (RAS) to control the further development of DN [4]. Furthermore, DN is an extremely complicated pathophysiological process, in which multiple biological and pathological processes are involved [5]. Therefore, it is imperative to develop an effective therapies and further understand the pathogenesis for DN. 
Astragali Radix Bunge (also called as Huangqi in Chinese) has been diffusely utilised as an essential ingredient in over 200 Chinese herb prescriptions to treat weakness, anorexia, chronic fatigue, uterine bleeding, anemia, diarrhea and uterine prolapsed [6, 7]. Currently, pharmacological experiments have showed that Astragali Radix possesses a wide variety of biological activities [8], including antioxidant, anti-aging, immunomodulation, anti-inflammation, antitumor, and anti-asthma pharmacological activities [9]. It is especially known to provide obviously protection against kidney, heart, liver, brain, intestine and lung injury [10]. Based on previous report, a derivative of Astragali Radix has a therapeutic effect for myocardial injury by ameliorating the myocardial index content [11]. Moreover, Astragali Radix has been used as a nutrient supplement or immunomodulatory natural herbal medicine in health food for reinforcing physique and nourishing tissues [12].

Network pharmacology proposed a new and efficient strategies for drug research by selecting potential signal nodes [13]. Moreover, it was aimed to study the function characteristics of drugs in biological systems with a holistic approach [14]. Nowadays, researchers have realized that the "one key, one lock" mode is inadequate to explain the drug effect, particularly in those complex diseases [15]. To explain the complex relationship between drug and diseases by network visualization and large amount of data analysis [16], a series of databases, tools, applications and scripts emerged [17]. Consequently, we analyzed the potential molecular pharmacological mechanism of the roles of Astragali Radix for DN through network pharmacology and experimental verification analysis.

\section{Material And Methods}

\section{Network pharmacology assay}

Traditional Chinese Medicine Systems Pharmacology (TCMSP) pharmacology platform (http://Isp.nwu.edu.cn/tcmsp.php) was chosen to obtain major ingredients and corresponding targets of Astragali Radix. The data of the bioactive ingredient of Astragali Radix was gained by screening oral bioavailability (OB) $\geq$ $30 \%$ with drug-like (DL) properties $\geq 0.18$. The genes concerning target were collected through the UniProt database (https://www.uniprot.org/). Gene Cards database (http://www.genecards.org/) and OMIM database (http://www.omim.org/) were utilised to select the targets of DN with "diabetic nephropathy" as the keyword. The Venny online tool (http://bioinfogp.cnb.csic.es/tools/venny/) was used to get same target genes between Astragali Radix and DN. Protein interaction network was constructed via the String database (https://stringdb.org/). GO analysis and KEGG enrichment results were performed via DAVID database (https://david.ncifcrf.gov/). FDR $<0.05$ is used as a screening criterion. The drug-ingredients-target-disease network was formed using Cytoscape 3.6.1 [18].

\section{Cell Culture}

The human renal epithelial HK-2 cell line (ATCC, Shanghai, China), was maintained in DMEM/F12 medium (Gibco, CA, USA) mixing $10 \%$ inactivated FBS (Gibco, CA, USA) at $37^{\circ} \mathrm{C}$ under $95 \%$ air and $5 \% \mathrm{CO}_{2}$.

\section{Cck-8 Assay}


HK-2 cells were incubated into $96-$ well plates $\left(5 \times 10^{4}\right.$ cells/well) and divided into control group $\left(5.5 \mathrm{mmol} \cdot \mathrm{L}^{-1}\right.$ glucose), high glucose group (30 mmol $\left.\cdot \mathrm{L}^{-1}\right)$, high glucose $\left(30 \mathrm{mmol} \cdot \mathrm{L}^{-1}\right)+50 \mu \mathrm{mol} \cdot \mathrm{L}^{-1}$ quercetin group and quercetin group $\left(5.5 \mathrm{mmol} \cdot \mathrm{L}^{-1}\right.$ glucose $+50 \mu \mathrm{mol} \cdot \mathrm{L}^{-1}$ quercetin) for $24 \mathrm{~h}$. Subsequently, CCK-8 solution (Biosharp Life Sciences, China) was supplemented at $37^{\circ} \mathrm{C}$ for an hour. Finally, the absorbance results were detected at $450 \mathrm{~nm}$ with a multi-well plate reader (Biotek, USA).

\section{Determination Of Antioxidant Parameters}

HK-2 cells were treated with high glucose $\left(30 \mathrm{mmol} \cdot \mathrm{L}^{-1}\right)$ and quercetin $\left(50 \mu \mathrm{mol} \cdot \mathrm{L}^{-1}\right)$ in 6 -well plates for $24 \mathrm{~h}$. Afterwards the HK-2 cells were collected to analyze the antioxidant activities of catalase (CAT) and superoxide dismutase (SOD). The indicators were measured according to the available manufacturer's instructions (Nanjing Jiancheng Bioengineering Institute, China).

\section{Western Blotting Analysis}

HK-2 cells were treated with high glucose $\left(30 \mathrm{mmol} \cdot \mathrm{L}^{-1}\right)$ and quercetin $\left(50 \mu \mathrm{mol} \cdot \mathrm{L}^{-1}\right)$ in 6 -well plates for $24 \mathrm{~h}$. HK-2 cells were collected and resuspended with $500 \mu \mathrm{L}$ cold phosphate buffered solution (PBS) buffer (Gibco, CA, USA). Protein sample concentrations were determined through bicinchoninic acid assay (BCA) protein sample assay kit after cell lysed (Kangwei Century Biotechnology, Beijing, China). Then the experimental protein samples were treated and separated by 6-12\% SDS-PAGE electrophoresis and subsequently transferred to activated PVDF membranes. Subsequently, membranes were blocked with $5 \%$ skim milk at room temperature (RT) for $2 \mathrm{~h}$ and incubated with primer antibodies against P38 MAPK, JNK, phosph-P38 MAPK, phosph-JNK, or $\beta$-actin (Cell Signaling Technology, USA) at $4{ }^{\circ} \mathrm{C}$ overnight. Next, membranes were correspondingly performed fluorescent secondary antibodies (Cell Signaling Technology, USA) at RT for $2 \mathrm{~h}$. Chemiluminescent protein bands were analyzed by Odyessey Imager (LI-COR, USA). ImageJ 1.41 software (Bethesda, USA) was used to calculate the optical density.

\section{Statistical analysis}

SPSS17.0 statistical software was offered for all data analysis. Values reported were expressed as means \pm SD. Student's $t$-test and two-way ANOVA were used to analyze significant differences. $P<0.05$ was set statistically significant..

\section{Results}

\section{Drug target prediction}

TCMSP database was performed to predict the candidate ingredients and targets from Astragali Radix. As shown in Table 1, a total of 12 compounds of Astragali Radix were obtained. 
Table 1

Potential effective ingredients of Astragali Radix

\begin{tabular}{|lllllll|}
\hline Molecule ID & Composition & Mr & OB/\% & DL & AlogP & Caco-2 \\
\hline MOL000098 & quercetin & 302.25 & 46.43 & 0.28 & 0.05 & 1.5 \\
\hline MOL000239 & jaranol & 314.31 & 50.83 & 0.29 & 0.61 & 2.09 \\
\hline MOL000296 & hederagenin & 414.79 & 36.91 & 0.75 & 1.32 & 8.08 \\
\hline MOL000354 & isorhamnetin & 316.28 & 49.6 & 0.31 & 0.31 & 1.76 \\
\hline MOL000371 & 3,9-di-O-methyInissolin & 314.36 & 53.74 & 0.48 & 1.18 & 2.89 \\
\hline MOL000378 & 7-O-methylisomucronulatol & 316.38 & 74.69 & 0.3 & 1.08 & 3.38 \\
\hline MOL000380 & A1 & 300.33 & 64.26 & 0.42 & 0.93 & 2.64 \\
\hline MOL000387 & bifendate & 418.38 & 31.1 & 0.67 & 0.15 & 2.56 \\
\hline MOL000392 & formononetin & 268.28 & 69.67 & 0.21 & 0.78 & 2.58 \\
\hline MOL000417 & calycosin & 284.28 & 47.75 & 0.24 & 0.52 & 2.32 \\
\hline MOL000422 & kaempferol & 286.25 & 41.88 & 0.24 & 1.77 & 0.26 \\
\hline MOL000442 & 1,7-dihydroxy-3,9-dimethoxy pterocarpene & 314.31 & 39.05 & 0.48 & 3.11 & 0.89 \\
\hline A1-(6aR,11aR)-9,10-dimethoxy-6a,11a-dihydro-6H-benzofurano[3,2-c]chromen-3-ol & & \\
\hline
\end{tabular}

\section{Intersection Target}

As a result, quercetin, kaempferol, 7-0-methylisomucronulatol, formononetin, isorhamnetin, hederagenin, 3,9-di-0methylnissolin, A1, calycosin, jaranol, bifendate and 1,7-dihydroxy-3,9-dimethoxy pterocarpene in Astragali Radix have $156,63,45,39,37,24,23,22,22,13,7$ and 4 targets respectively from the Drugbank database. 95 targets for the effective ingredients of Astragali Radix were obtained after deleting the duplicate targets. Data mentioned above indicates that the effective ingredients of Astragali Radix have multiple targets. Moreover, We speculated that quercetin of Astragali Radix was the most likely natural active ingredient to treat DN. By searching the keyword "diabetic nephropathy" in the Gene Cards and OMIM disease database, 2418 disease targets were obtained. As shown in Fig. 1, 56 same targets between Astragali Radix and DN in totally are obtained. And specific information is described in Table 2. 
Table 2

Potential targets of Astragali Radix for treatment of DN

\begin{tabular}{|c|c|c|c|c|c|c|c|}
\hline No. & $\begin{array}{l}\text { Gene } \\
\text { name }\end{array}$ & Protein name & $\begin{array}{l}\text { UniProt } \\
\text { ID }\end{array}$ & No. & $\begin{array}{l}\text { Gene } \\
\text { name }\end{array}$ & Protein name & $\begin{array}{l}\text { UniProt } \\
\text { ID }\end{array}$ \\
\hline 1 & PTGS1 & $\begin{array}{l}\text { Prostaglandin } \mathrm{G} / \mathrm{H} \\
\text { synthase } 1\end{array}$ & P23219 & 29 & GSTM1 & $\begin{array}{l}\text { Glutathione S-transferase } \\
\text { Mu } 1\end{array}$ & P09488 \\
\hline 2 & AR & Androgen receptor & Q13771 & 30 & EGFR & $\begin{array}{l}\text { Epidermal growth factor } \\
\text { receptor }\end{array}$ & P00533 \\
\hline 3 & ESR2 & $\begin{array}{l}\text { Estrogen receptor } \\
\text { beta }\end{array}$ & Q92731 & 31 & VEGFA & $\begin{array}{l}\text { Vascular endothelial } \\
\text { growth factor A }\end{array}$ & P15692 \\
\hline 4 & PRSS1 & Trypsin-1 & P07477 & 32 & CCND1 & G1/S-specific cyclin-D1 & P24385 \\
\hline 5 & CHRM2 & $\begin{array}{l}\text { Muscarinic } \\
\text { acetylcholine } \\
\text { receptor M2 }\end{array}$ & P08172 & 33 & PPARG & $\begin{array}{l}\text { Peroxisome proliferator } \\
\text { activated receptor } \\
\text { gamma }\end{array}$ & P37231 \\
\hline 6 & $\mathrm{ADH} 1 \mathrm{~B}$ & $\begin{array}{l}\text { Alcohol } \\
\text { dehydrogenase 1B }\end{array}$ & P00325 & 34 & CASP9 & Caspase-9 & P55211 \\
\hline 7 & ESR1 & Estrogen receptor & Q5T5H8 & 35 & PLAU & $\begin{array}{l}\text { Urokinase-type } \\
\text { plasminogen activator }\end{array}$ & P00749 \\
\hline 8 & FOS & $\begin{array}{l}\text { Proto-oncogene c- } \\
\text { Fos }\end{array}$ & P01100 & 36 & RB1 & $\begin{array}{l}\text { Retinoblastoma- } \\
\text { associated protein }\end{array}$ & P06400 \\
\hline 9 & AKR1B1 & Aldose reductase & P15121 & 37 & IL6 & Interleukin-6 & P05231 \\
\hline 10 & F7 & $\begin{array}{l}\text { Coagulation factor } \\
\text { VII }\end{array}$ & P08709 & 38 & ELK1 & $\begin{array}{l}\text { ETS domain-containing } \\
\text { protein Elk-1 }\end{array}$ & P19419 \\
\hline 11 & $\mathrm{ACHE}$ & Acetylcholinesterase & P22303 & 39 & CASP8 & Caspase-8 & Q14790 \\
\hline 12 & RELA & $\begin{array}{l}\text { Transcription factor } \\
\text { p65 }\end{array}$ & Q04206 & 40 & RAF1 & $\begin{array}{l}\text { RAF proto-oncogene } \\
\text { serine/threonine-protein } \\
\text { kinase }\end{array}$ & P04049 \\
\hline 13 & OLR1 & $\begin{array}{l}\text { Oxidized low-density } \\
\text { lipoprotein receptor } \\
1\end{array}$ & P78380 & 41 & SLC2A4 & $\begin{array}{l}\text { Solute carrier family } 2 \text {, } \\
\text { facilitated glucose } \\
\text { transporter member } 4\end{array}$ & P14672 \\
\hline 14 & $\mathrm{BCL2}$ & $\begin{array}{l}\text { Apoptosis regulator } \\
\text { Bcl-2 }\end{array}$ & P10415 & 42 & HIF1A & $\begin{array}{l}\text { Hypoxia-inducible factor } \\
\text { 1-alpha }\end{array}$ & Q16665 \\
\hline 15 & CASP3 & Caspase-3 & P42574 & 43 & ERBB2 & $\begin{array}{l}\text { Receptor tyrosine-protein } \\
\text { kinase erbB-2 }\end{array}$ & P04626 \\
\hline 16 & MAPK8 & $\begin{array}{l}\text { Mitogen-activated } \\
\text { protein kinase } 8\end{array}$ & P45983 & 44 & CAV1 & Caveolin-1 & Q03135 \\
\hline 17 & CYP3A4 & $\begin{array}{l}\text { Cytochrome P450 } \\
\text { 3A4 }\end{array}$ & P08684 & 45 & MYC & $\begin{array}{l}\text { Myc proto-oncogene } \\
\text { protein }\end{array}$ & P01106 \\
\hline 18 & CYP1A1 & $\begin{array}{l}\text { Cytochrome P450 } \\
1 \mathrm{~A} 1\end{array}$ & P04798 & 46 & DUOX2 & Dual oxidase 2 & Q9NRD8 \\
\hline 19 & ICAM1 & $\begin{array}{l}\text { Intercellular } \\
\text { adhesion molecule } \\
1\end{array}$ & P05362 & 47 & NOS3 & $\begin{array}{l}\text { Nitric oxide synthase, } \\
\text { endothelial }\end{array}$ & P29474 \\
\hline
\end{tabular}




\begin{tabular}{|c|c|c|c|c|c|c|c|}
\hline No. & $\begin{array}{l}\text { Gene } \\
\text { name }\end{array}$ & Protein name & $\begin{array}{l}\text { UniProt } \\
\text { ID }\end{array}$ & No. & $\begin{array}{l}\text { Gene } \\
\text { name }\end{array}$ & Protein name & $\begin{array}{l}\text { UniProt } \\
\text { ID }\end{array}$ \\
\hline 20 & SELE & E-selectin & P16581 & 48 & HSPB1 & Heat shock protein beta-1 & P04792 \\
\hline 21 & VCAM1 & $\begin{array}{l}\text { Vascular cell } \\
\text { adhesion protein } 1\end{array}$ & P19320 & 49 & MGAM & $\begin{array}{l}\text { Maltase-glucoamylase, } \\
\text { intestinal }\end{array}$ & 043451 \\
\hline 22 & CYP1B1 & $\begin{array}{l}\text { Cytochrome P450 } \\
\text { 1B1 }\end{array}$ & Q16678 & 50 & CCNB1 & $\begin{array}{l}\text { G2/mitotic-specific cyclin- } \\
\text { B1 }\end{array}$ & P14635 \\
\hline 23 & ALOX5 & $\begin{array}{l}\text { Arachidonate 5- } \\
\text { lipoxygenase }\end{array}$ & P09917 & 51 & NFE2L2 & $\begin{array}{l}\text { Nuclear factor erythroid 2- } \\
\text { related factor } 2\end{array}$ & Q16236 \\
\hline 24 & GSTP1 & $\begin{array}{l}\text { Glutathione S- } \\
\text { transferase P }\end{array}$ & P09211 & 52 & NQ01 & $\begin{array}{l}\mathrm{NAD}(\mathrm{P}) \mathrm{H} \text { dehydrogenase } \\
\text { [quinone] } 1\end{array}$ & P15559 \\
\hline 25 & AHR & $\begin{array}{l}\text { Aryl hydrocarbon } \\
\text { receptor }\end{array}$ & P35869 & 53 & PARP1 & $\begin{array}{l}\text { Poly [ADP-ribose] } \\
\text { polymerase } 1\end{array}$ & Q5VX85 \\
\hline 26 & PRKCA & $\begin{array}{l}\text { Protein kinase } C \\
\text { alpha type }\end{array}$ & P17252 & 54 & COL3A1 & $\begin{array}{l}\text { Collagen alpha-1(III) } \\
\text { chain }\end{array}$ & P02461 \\
\hline 27 & CRP & C-reactive protein & P02741 & 55 & IGFBP3 & $\begin{array}{l}\text { Insulin-like growth factor- } \\
\text { binding protein } 3\end{array}$ & P17936 \\
\hline 28 & IGF2 & $\begin{array}{l}\text { Insulin-like growth } \\
\text { factor II }\end{array}$ & P01344 & 56 & PON1 & $\begin{array}{l}\text { Serum } \\
\text { paraoxonase/arylesterase } \\
1\end{array}$ & P27169 \\
\hline
\end{tabular}

\section{Protein interaction network analysis}

As shown in Fig. 2, the network is interrelated among the 56 targets. Moreover, it shows that 56 targets play an important role in DN through multi-channel and multi-directional coordination.

\section{Go Analysis}

We entered 56 same target genes, further, "person" was selected as the species, yielding 20 enrichment results to the DAVID database. The ggplot2.R package (3.2.0 Version) was ready for visualization. The biological processes mainly include protein homodimerization activity, proximal promoter sequence-specific DNA binding, DNA-binding transcription activator activity and cofactor binding. As shown in Fig. 3, the size of the dots represents the number of genes included, and the color changes from blue to red indicates a gradual increase in significance. The protein homodimerization activity contains 11 genes and the gene rate is $19.64 \%$. Therefore, this may become a potential research direction of Astragali Radix for treatment of DN.

\section{Kegg Pathway Analysis}

Furthermore, we further imported 56 same target genes, "person" was also selected as the species, producing 13 enrichment results. The enrichment of results was shown in Fig. 4. The potential targets network of Astragali Radix for treatment of DN is mainly related to MAPK, HIF, p53 and NF-KB signaling pathway. Results indicated that the target of Astragali Radix for treatment of DN was distributed in different metabolic pathways, and multicomponent and multi-target interaction may be the mechanism for treating DN. As shown in Fig. 5, the pathway 
map of Astragali Radix for treatment of DN using KEGG Mapper. Those top-ranking signaling pathways from KEGG analysis were integrated and mapped to obtain the final path map. The 13 targets of Astragali Radix for treatment of DN was marked in red, and the proportion was $23.21 \%$. Moreover, the results showed that the targets of Astragali Radix for treatment of DN was connected with MAPK, HIF, p53, CASP, Elk1, TNF and NF-KB signaling pathway. It demonstrated that the targets of Astragali Radix for treatment of DN was mainly distributed in these signaling pathways, which probably through the interaction of several links to show therapeutic effect.

\section{Drug-ingredients-target-disease Network}

Cytoscape 3.6.1 was utilised to build the drug-ingredients-target-disease network of Astragali Radix. The results were shown in Fig. 6. This network contains 70 nodes (1 drug, 12 effective ingredients, 56 targets and 1 disease). The drug, diseases, ingredients and targets respectively used V-shaped, V-shaped, elliptical and rectangular nodes, and the relationship was represented by edges. The more action targets were connected, the greater treatment effect of DN, in which quercetin of Astragali Radix may be potential material basis for therapeutic effects. There were 56 targets for Astragali Radix for treatment of DN, among which GSTP1, NQ01, NOS3[19] were related to oxidative stress [20], and IL-6 was related to inflammation [21], furthermore, MAPK8, CASP3 and BCL2 were related to apoptosis [22]. Therefore, it is presumed that quercetin of Astragali Radix has the most potential to treat DN mainly through inhibiting oxidative stress, inflammatory reaction and apoptosis in the body.

\section{Quercetin attenuates cytotoxicity in high glucose-induced HK-2 cells}

Quercetin from Astragali Radix is a potential natural active product for the treatment of DN, which has the chemical structure of ortho phenolic hydroxyl (Fig. 7A). To investigate the effects of quercetin on the cytotoxicity of high glucose-treated renal cells, HK-2 cells were incubated with high glucose $\left(30 \mathrm{mmol} \cdot \mathrm{L}^{-1}\right)$ and/or quercetin $\left(50 \mu \mathrm{mol} \cdot \mathrm{L}^{-1}\right)$. The experimental result meant that quercetin treatment significantly improved cell viability in high glucose-induced HK-2 cells (Fig. 7B).

\section{Quercetin enhances antioxidant capacity in high glucose-induced HK-2 cells}

The activities of antioxidant-related enzymes may be used as an indicator to reflect the antioxidant status. Therefore, the antioxidant capacity were determined to certify the protective roles of quercetin on high glucoseinduced oxidative stress. As shown in Fig. 7C-D, antioxidant parameters SOD and CAT were significantly decreased in high glucose group. On the contrary, quercetin could significantly enhance SOD and CAT activities in high glucose-induced HK-2 cells.

\section{Quercetin regulates MAPK signaling pathway in high glucose-induced HK-2 cells}

In order to further study the molecular mechanisms of quercetin in the treatment of DN, we analyzed the effect of quercetin on MAPK signaling pathway. Western blot analysis results showed high glucose could increase phosphorylation of P38 MAPK and JNK. However, treatment with quercetin significantly suppressed the phosphorylation of P38 MAPK and JNK in MAPK signaling pathway (Fig. 8).

\section{Discussion}


Studies have shown that kidney damage is the most severe in DN, and the damage can aggravate the risk of kidney disease. Importantly, the acute and chronic high glucose state can inhibit the growth of kidney-related cells, further causing cell inflammation, and then induce apoptosis. Network pharmacological method can be useful in providing a global picture of the disease pathogenesis and to identify potential new drug targets for DN. Our results confirmed the evaluation system of DN based on network pharmacology method. Meanwhile, it also revealed that key nodes were selected to get the pathway enrichment by combining GO with KEGG analysis. To explore the correlation between Astragali Radix and DN from a integral direction, network pharmacology can offer a novel strategy for in-depth research of TCM due to its holistic and systematic.

Here, TCMSP database could predict the potential effective ingredients and targets from Astragali Radix. As shown in Table 1, after deleting the components without corresponding targets, a total of 12 compounds of Astragali Radix were found. Upon the analysis data of Gene Cards and OMIM database for DN disease targets, 56 same target genes between Astragali Radix and DN could be obtained. As shown in Fig. 1 and Table 2, the data of Astragali Radix in the treatment of DN revealed that the same target genes included IL6, RELA, CASP3, CASP8, CASP9, BCL2, MAPK8, NQ01, PTGS1, HIF1A, VCAM1, CYP3A4, CYP1A1, GSTM1 and PPARG, which were involved in many biological processes, such as inflammation, oxidative stress [23], apoptosis, aging [24]. As well documented, researches have certified that inflammation reaction plays a pivotal role in DN [25]. High blood sugar may cause the accumulation of advanced glycation end products, which leads to inflammation in the human kidney cells, increases cell apoptosis, and accelerates the development of DN [26]. Besides, it is reported that the pathogenesis of DN is closely correlated with oxidative stress and apoptosis [27]. The drug protects rats from DN by reducing the expression of IL-1 $1 \beta, \mathrm{IL}-6$, and TNF-a inflammatory cytokines and inhibiting the oxidative stress response mediated by hyperglycemia [28]. Based on the results above, they indicate that Astragali Radix could treat DN by ameliorating these mentioned biological processes. Here, protein interaction networks analysis using the String database indicates that the same targets between Astragali Radix and DN are interrelated and play a positive effect in DN through multi-channel and multi-faceted coordination (Fig. 2).

Enrichment analysis showed that the therapeutic effects of Astragali Radix mainly involved the biological process of oxidative stress, inflammatory reaction and apoptosis. The signaling pathways concerning Astragali Radix for treatment of DN largely related to MAPK, HIF, p53 and NF-KB signaling pathway. These pathways may be the future direction of research in the treatment of DN. GO analysis results displayed that the biological processes included protein homodimerization activity and proximal promoter sequence-specific DNA binding (Fig. 3). The above-mentioned molecular functions were associated with various genes and were significant. So the biological processes may become potential research directions of Astragali Radix for treatment of DN. As shown in Figs. 4 and 5, KEGG analysis results were mainly contained p53, MAPK, HIF and NF-KB signaling pathway. More importantly, the potential targets were most closely linked to the MAPK signaling pathway. p53 is a tumor suppressor [29]. It can respond rapidly to genotoxic stresses caused by DNA damage and induce caspase-9 activation and BCL-2 expression, leading to accelerated cell apoptosis [30]. MAPK signaling pathway, including P38 and JNK, mediates cell apoptosis through combining a complex with a proapoptotic factor of p53 [31]. In addition, it can motivate the expression of inflammatory factors mediated through NF-KB signaling pathways and accelerate the kidney pathological changes [32]. HIF-1 was increased in DN mice, which mediates DN-induced kidney fibrotic disease [33]. NF-KB is a key transcription factor regulating inflammatory response in DN. Besides, inflammatory cytokines could stimulate the protein expression of NF-kB signaling pathway [34]. It indicated that the target of Astragali Radix for DN treatment was distributed in various metabolic pathways. As shown in Fig. 6, the drug-ingredients-target-disease network of Astragali Radix was drawn by Cytoscape software. The results

Page 9/21 
showed that drugs, ingredients, targets and diseases coordinate with each other. In addition, the treatment of Astragali Radix in DN was through the regulation of multi-component, multi-target, and multi-pathway. Meanwhile, its mechanism mainly involved anti-inflammatory, antioxidation and anti-apoptosis.

Although the above results manifested that the molecular pharmacological mechanism of Astragali Radix in DN treatment from network pharmacology, there were still some limitations. Then we conducted an experimental verification in the next research. Network pharmacology analysis results prompted quercetin from Astragali Radix had the most effective suppression ability against high glucose-induced HK-2 cells owing to ranking first among other ingredients. Therefore, quercetin was chosen as the most representative bioactive ingredient of Astragali Radix for further molecular pharmacology experiments. Moreover, KEGG analysis suggested MAPK signaling pathway were the most potential pathway on the treatment of Astragali Radix in DN. In this study, quercetin remarkably reduced high glucose-induced cytotoxicity of HK-2 cells (Fig. 7B). Oxidative stress is an obvious trigger for DN, which is induced by continuously accumulation of advanced glycation end metabolites in the kindey tissue [35]. Additionally, antioxidant enzymes can scavenge mass production of reactive oxygen species (ROS) to maintain the balance in redox system [36]. CAT and SOD are essential antioxidant elements, they form a mutually supportive defense system against ROS [37]. Further analysis certified that enhancement of antioxidant ability may be the underlying molecular mechanism by which quercetin inhibited high glucose-induced renal cell apoptosis. In our experiments, quercetin treatment dramatically induced an increase of CAT and SOD activities in high glucose-induced HK-2 cells (Fig. 7C-D). Finally, our results verified the ameliorative role of quercetin in high

glucose-induced HK-2 cells by regulating MAPK signaling pathway. In our experiments, quercetin inhibited the phosphorylation of P38 MAPK and JNK, due to significantly reduction of cell apoptosis (Fig. 8).

\section{Conclusion}

Here, we confirmed the positive effect of Astragali Radix on DN via network pharmacology. Results showed that Astragali Radix could act on multi-target and play a potential therapeutic role on DN by multi-pathway. Molecular mechanism analysis showed that it mainly involved anti-inflammatory, antioxidation and anti-apoptosis. Additionally, experimental analysis demonstrated the therapeutic function of quercetin from Astragali Radix by improving antioxidant capacity and suppressing MAPK signaling pathway, which could generate a theoretical foundation for further research of the molecular pharmacological mechanism of Astragali Radix in the process of DN treatment.

\section{Abbreviations}

\section{DN}

Diabetic nephropathy; TCMSP:Traditional Chinese Medicine Systems Pharmacology; GO:Gene Ontology; KEGG:Kyoto Encyclopedia of Genes and Genomes; DAVID:Database for Annotation, Visualization and Integrated Discovery; OB:oral bioavailability; DL:drug-like; CAT:cytotoxicity, enhance catalase; SOD:superoxide dismutase; ESRD:end-stage renal disease; RAS:renin-angiotensin system; PBS:phosphate buffered solution; BCA:bicinchoninic acid assay; RT:room temperature.

\section{Declarations}

\section{Authors' contributions}


TCM, CX and XDZ conceived and designed the study. TCM, CX and CJB collected the data. TCM performed the data analysis and wrote the manuscript. All authors are responsible for reviewing data. All authors read and approved the final manuscript.

\section{Author details}

${ }^{1}$ Department of Pharmacy, Shaoxing Hospital of Traditional Chinese Medicine, Shaoxing 312000, China. ${ }^{2}$ College of Pharmaceutical Sciences, Zhejiang Chinese Medical University, Hangzhou, Zhejiang, 310053, China.

\section{Acknowledgements}

Not applicable.

\section{Competing interests}

The authors have declared that there is no conflict of interest.

\section{Availability of data and materials}

The datasets used and analyzed during the current study are available from the corresponding author on reasonable request.

TCMSP repository, http://tcmspw.com/tcmsp.php.

Gene Cards database, http://www.genecards.org/.

UniProt database, https://www.uniprot.org/.

Venny online tool, http://bioinfogp.cnb.csic.es/tools/venny/.

String database, https://string-db.org/.

\section{Consent for publication}

Not applicable.

\section{Ethics approval and consent to participate}

Not applicable.

\section{Funding}

Project supported by the National Natural Science Foundation of China (Grant No. 81673656, 81374048), and the Opening Project of Zhejiang Provincial Preponderant and Characteristic Subject of Key University (Traditional Chinese Pharmacology), Zhejiang Chinese Medical University (ZYAOXZD2019002).

\section{References}

1. Cao X, Gong X, Ma X. Diabetic nephropathy versus niabetic retinopathy in a chinese population: a retrospective study. Med Sci Monit. 2019;25:6446-53. 
2. Chen HY, Pan HC, Chen YC, Chen YC, Lin YH, Yang SH, Chen JL, Wu HT. Traditional Chinese Medicine use is associated with lower end-stage renal disease and mortality rates among patients with diabetic nephropathy: a population-based cohort study. BMC Complement Altern Med. 2019;19:81-93.

3. Gilbert RE. Proximal tubulopathy: prime mover and key therapeutic target in diabetic kidney disease. Diabetes. 2017;66:791-800.

4. Barutta F, Bernardi S, Gargiulo G, Durazzo M, Gruden G. SGLT2 inhibition to address the unmet needs in diabetic nephropathy. Diabetes Metab Res Rev. 2019;35:e3171-83.

5. Wang GW, Li QY, Chen DF, Wu BH, Wu YL, Tong WJ, Huang PT. Kidney-targeted rhein-loaded liponanoparticles for diabetic nephropathy therapy via size control and enhancement of renal cellular uptake. Theranostics. 2019;9:6191-208.

6. Guo ZZ, Lou YM, Kong MY, Luo Q, Liu ZQ, Wu JJ. A systematic review of phytochemistry, pharmacology and pharmacokinetics on Astragali Radix. implications for Astragali Radix as a personalized medicine. Int J Mol Sci. 2019;20:1463-506.

7. Gong AGW, Duan R, Wang HY, Kong XP, Dong TTX, Tsim KW, Chan K. Evaluation of the pharmaceutical properties and value of Astragali Radix. Medicines. 2018;5:46-61.

8. Jung Y, Jerng U, Lee S. A systematic review of anticancer effects of radix astragali. Chin J Integr Med. 2016;22:225-36.

9. Lou YM, Guo ZZ, Zhu YF, Zhang GY, Wang Y, Qi XX, Lu LL, Liu ZQ, Wu JJ. Astragali radix and its main bioactive compounds activate the Nrf2-mediated signaling pathway to induce P-glycoprotein and breast cancer resistance protein. J Ethnopharmacol. 2019;228:82-91.

10. Wang FG, Chen SX, Deng L, Chen L, Huang YW, Tian M, Li CJ, Zhou X. Protective effects of Astragaloside IV against LPS-induced endometritis in mice through inhibiting activation of the NF-KB, p38 and JNK signaling pathways. Molecules. 2019;24:373-85.

11. Tsai CC, Wu HH, Chang CP, Lin $\mathrm{CH}$, Yang HH. Calycosin-7-O- $\beta$-D-glucoside reduces myocardial injury in heat stroke rats. J Formos Med Assoc. 2019;118:730-8.

12. Chen ZJ, Liu LJ, Gao CF, Chen WJ, Vong CT, Yao PF, Yang YH, Li XZ, Tang XD, Wang SP, Wang YT. 2020. Astragali Radix (Huangqi): A promising edible immunomodulatory herbal medicine. J Ethnopharmacol. 258. 112895-112912.

13. Chen Q, Zheng J, Shao Y, Ai N, Wu L, Liu Y, Lu X, Fan X. Network-based assessment on chemical-induced cholestatic liver injury. Curr Top Med Chem. 2016;16:3668-77.

14. Hou Y, Nie Y, Cheng B, Tao J, Ma X, Jiang M, Gao J, Bai G. Qingfei Xiaoyan Wan, a traditional Chinese medicine formula, ameliorates Pseudomonas aeruginosa-induced acute lung inflammation by regulation of PI3K/AKT and Ras/MAPK pathways. Acta pharmaceutica Sinica B. 2016;6:212-21.

15. Guney E, Menche J, Vidal M, Barábasi AL. Network-based in Silico Drug Efficacy Screening. Nat Commun. 2016;7:10331-43.

16. Athanasios A, Charalampos V, Vasileios T, Ashraf GM. Protein-protein interaction (PPI) network: recent advances in drug discovery. Curr Drug Metab. 2017;18:5-10.

17. Kanehisa M, Furumichi M, Tanabe M, Sato Y, Morishima K. KEGG: new perspectives on genomes, pathways, diseases and drugs. Nucleic Acids Res. 2017;45:D353-61.

18. Liu LH, Du B, Zhang HY, Guo XF, Zhou Z, Xiu AH, Liu C, Su SY, Ai H. A network pharmacology approach to explore the mechanisms of Erxian decoction in polycystic ovary syndrome. Chin Med. 2018;13:46. 
19. Kubben N, Zhang W, Wang L, Voss TC, Yang J, Qu J, Liu GH, Misteli T. Repression of the antioxidant NRF2 pathway in premature aging. Cell. 2016;165:1361-74.

20. Sas K, Szabo E, Vecsei L. 2018. Mitochondria, oxidative stress and the kynuren-ine system, with a focus on ageing and neuroprotection. Molecules 23: 191.

21. Zhang R, Liu Y, Xing L, Zhao N, Zheng Q, Li J. 2018. The protective role of selenium against cadmium-induced hepatotoxicity in laying hens: expression of Hsps and inflammation-related genes and modulation of elements homeostasis. Ecotoxicol Environ Saf. 159: 205-212.

22. Hassanein EHM, Shalkami AS, Khalaf MM, Mohamed WR, Hemeida RAM. The impact of Keap1/Nrf2, P38 MAPK/NF-KB and Bax/Bcl2/caspase-3 signaling pathways in the protective effects of berberine against methotrexate-induced nephrotoxicity. Biomed Pharmacother. 2019;109:47-56.

23. Mansour DF, Saleh DO, Mostafa RE. Genistein ameliorates cyclophospha-mide -induced hepatotoxicity by modulation of oxidative stress and inflammatory mediators. Open Access Maced J Med Sci. 2019;5:836-43.

24. Baar MP, Brandt RMC, Putavet DA, Klein JDD, Derks KWJ, Bourgeois BRM, Stryeck S, Rijksen Y, van Willigenburg H, Feijtel DA, van der Pluijm I, Essers J, van Cappellen WA, van IJcken WF, Houtsmuller AB, Pothof J, de Bruin RWF, Madl T, Hoeijmakers JHJ, Campisi J, de Keizer PLJ. Targeted apoptosis of senescent cells restores tissue homeostasis in response to chemotoxicity and aging. Cell. 2017;169:132-47.

25. Dugbartey GJ. Diabetic nephropathy: a potential savior with 'rotten-egg'smell. Pharmacol Rep. 2017;69:331-9.

26. Lv N, Li CQ, Liu X, Qi CH, Wang ZQ. miR-34b alleviates high glucose-induced inflammation and apoptosis in human HK-2 cells via IL-6R/JAK2/STAT3 signaling pathway. Med Sci Monit. 2019;25:8142-51.

27. Ma X, Jiao Z, Liu Y, Chen J, Li G, Liu T, Tse G, Yuan R. Probucol protects against contrast-induced acute kidney injury via the extracellular signal-regulated kinases 1 and 2 (ERK1/2)/JNK-caspase 3 pathway in diabetic rats. Med Sci Monit. 2019;25:1038-45.

28. Nair V, Komorowsky CV, Weil EJ, Yee B, Hodgin J, Harder JL, Godfrey B, Ju W, Boustany-Kari CM, Schwarz M, Lemley KV, Nelson PJ, Nelson RG, Kretzler M. A molecular morphometric approach to diabetic kidney disease can link structure to function and outcome. Kidney Int. 2018;93:439-49.

29. Lazo PA. Reverting p53 activation after recovery of cellular stress to resume with cell cycle progression. Cell Signal. 2017;33:49-58.

30. Fischer NW, Prodeus A, Malkin D, Gariépy J. p53 oligomerization status modulates cell fate decisions between growth, arrest and apoptosis. Cell Cycle. 2016;15:3210-9.

31. Lai MC, Liu WY, Liou SS, Liu IM. The protective effects of moscatilin against methylglyoxal-induced neurotoxicity via the regulation of p38/JNK MAPK pathways in PC12 neuron-like cells. Food Chem Toxicol. 2020;140:111369-78.

32. Xu F, Xu J, Xiong X, Deng Y. Salidroside inhibits MAPK, NF-KB, and STAT3 pathways in psoriasis-associated oxidative stress via SIRT1 activation. Redox Rep. 2019;24:70-4.

33. Nayak BK, Shanmugasundaram K, Friedrichs WE, Cavaglierii RC, Patel M, Barnes J, Block K. HIF-1 mediates renal fibrosis in OVE26 type 1 diabetic mice. Diabetes. 2016;65:1387-97.

34. Yi H, Peng R, Zhang LY, Sun Y, Peng HM, Liu HD, Yu LJ, Li AL, Zhang YJ, Jiang WH, Zhang Z. LincRNA-Gm4419 knockdown ameliorates NF-kB/NLRP3 inflammasome-mediated inflammation in diabetic nephropathy. Cell Death Dis. 2017;8:e2583-96.

35. Pradeep SR, Srinivasan K. Alleviation of oxidative stress-mediated nephropathy by dietary fenugreek (trigonella foenum-graecum) seeds and onion (allium cepa) in streptozotocin-induced diabetic rats. Food 
Funct. 2018;9:134-48.

36. Liu D, Wu M, Li L, Gao X, Yang B, Mei S, Fu L, Mei C. Low-protein diet supplemented with ketoacids delays the progression of diabetic nephropathy by inhibiting oxidative stress in the KKAy mice model. Br J Nutr. 2018;119:22-9.

37. Karimi Z, Ghaffari M, Dolatabadi JN, Dehghan P. The protective effect of thymoquinone on tertbutylhydroquinone induced cytotoxicity in human umbilical vein endothelial cells. Toxicol Res. 2019;8:10506.

\section{Figures}

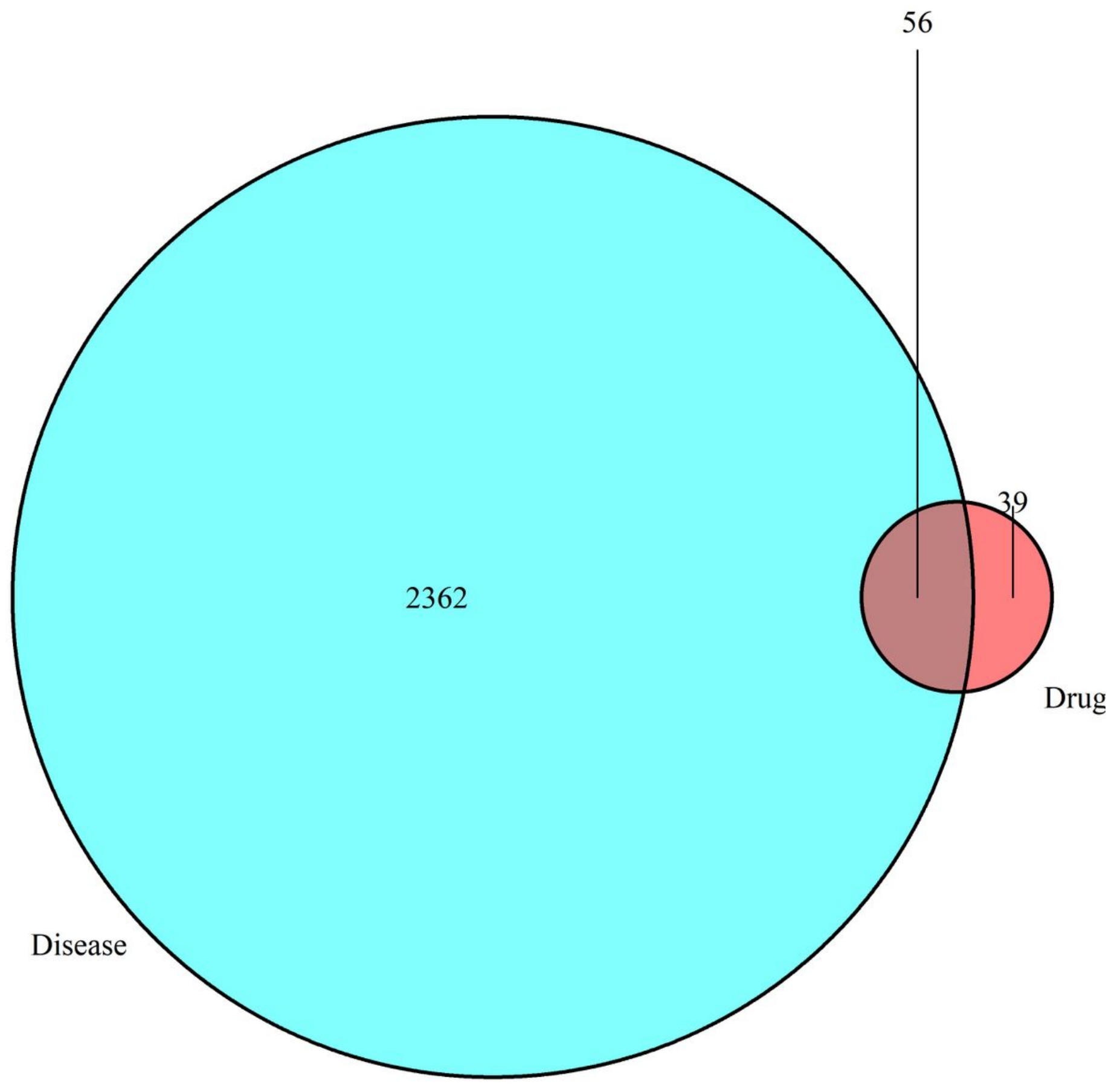




\section{Figure 1}

Venn diagram of Astragali Radix and DN targets.

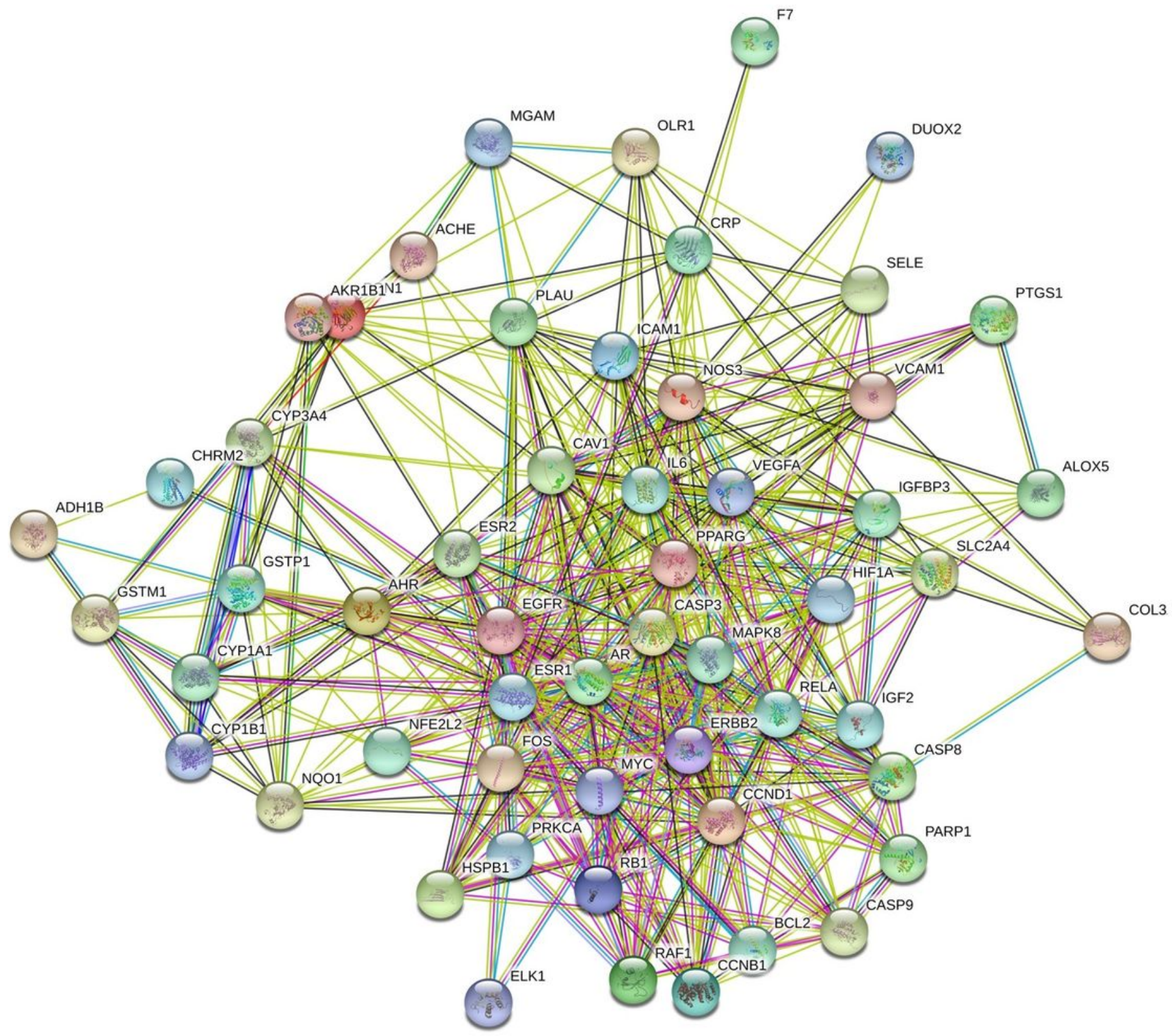

Figure 2

Interaction network of potential targets of Astragali Radix for treatment of DN. Nodes-proteins; Edges-proteinprotein associations; Light blue line-data from curated databases; Purple line-data by experimentally determined; Green and dark blue line-the Predicted interaction of genetic neighborhood or gene co-occurrence; yellow line-data by extmining; black line: co-expression. 


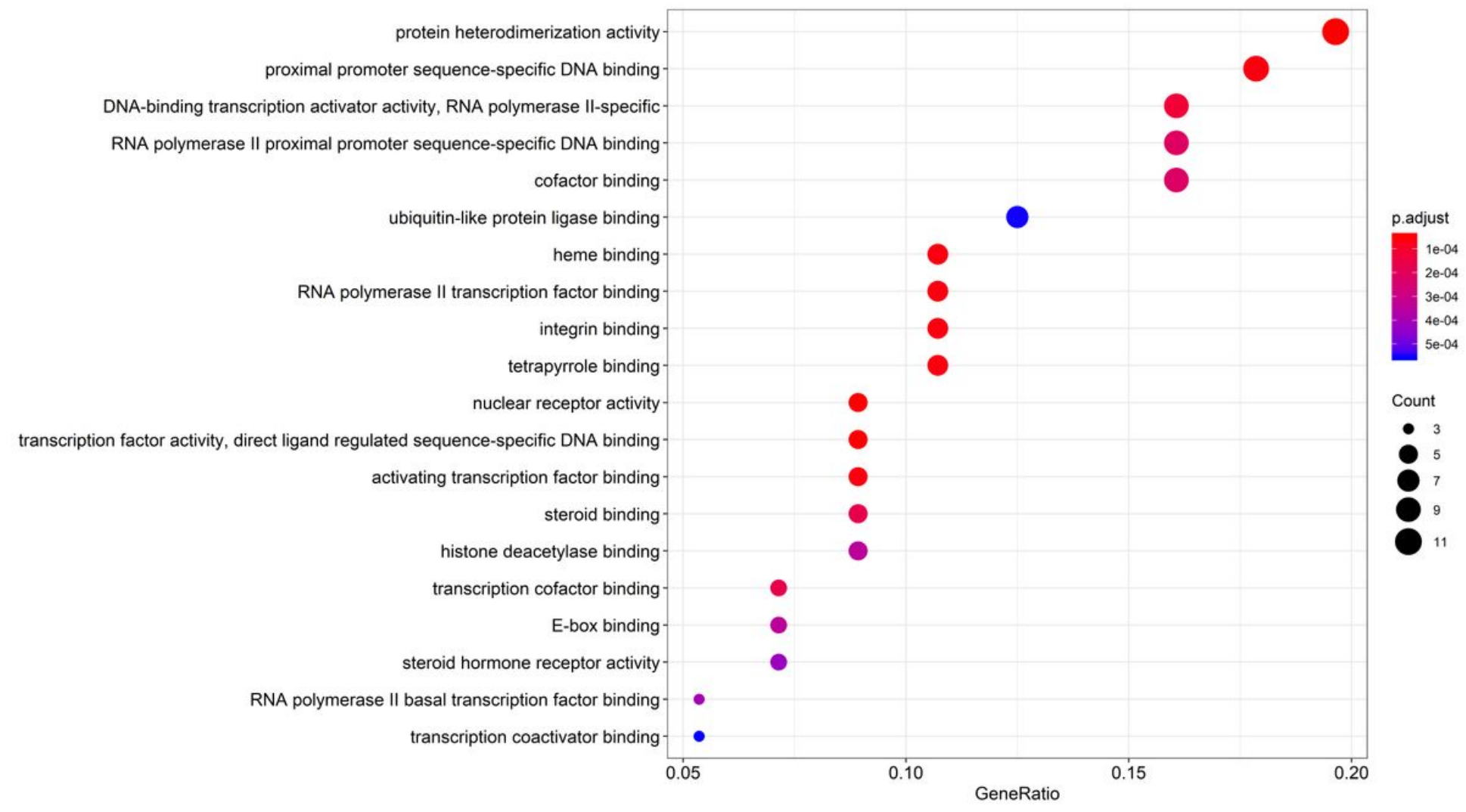

\section{Figure 3}

GO analysis of potential targets of Astragali Radix for treatment of DN. The ggplot2.R package (3.2.0 Version) was used for visualization. The size of the dots represents the number of genes included, and the color changes from blue to red indicates a gradual increase in significance. 


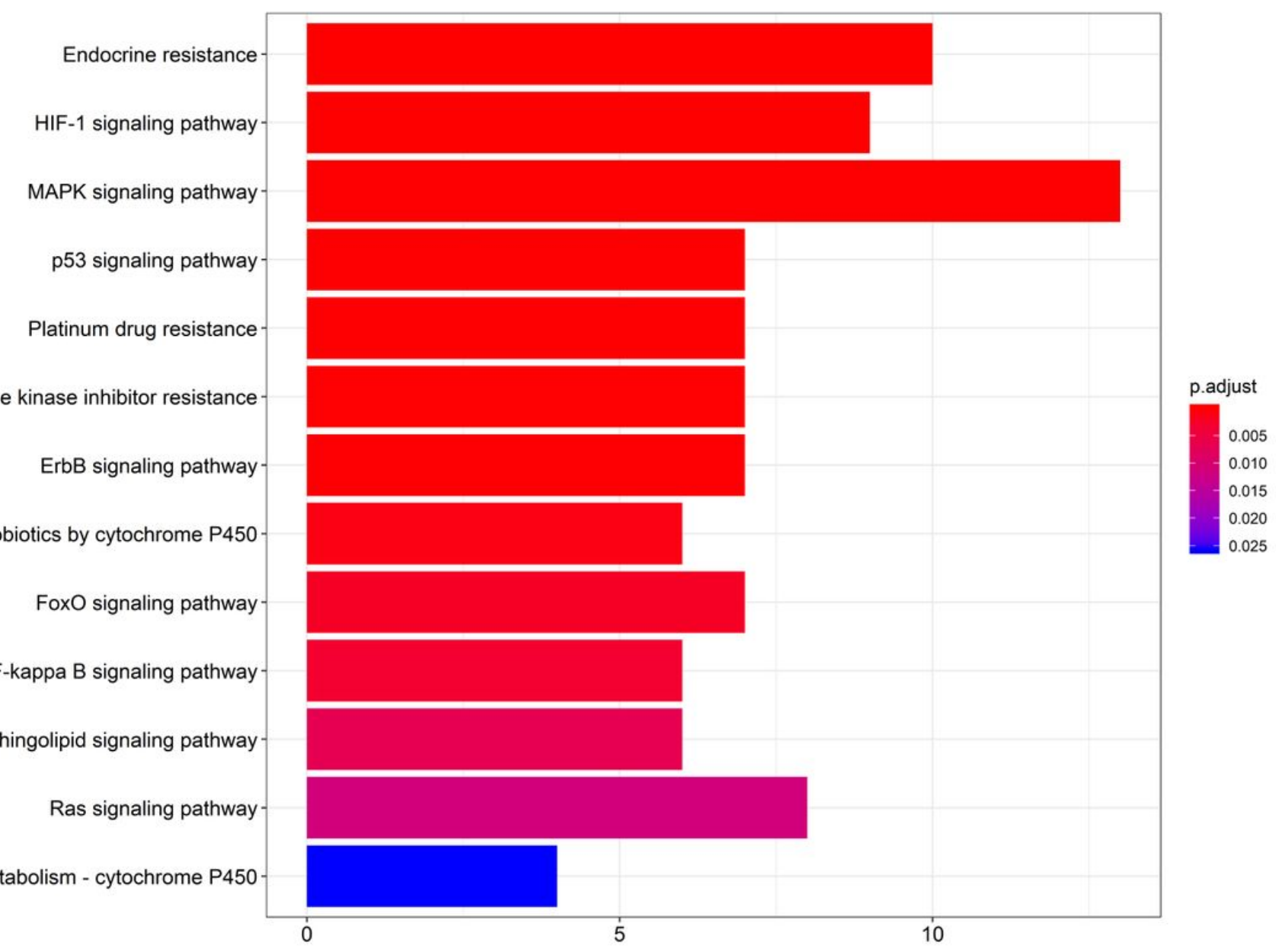

Figure 4

Enrich KEGG pathways analysis of potential targets of Astragali Radix for treatment of DN. 


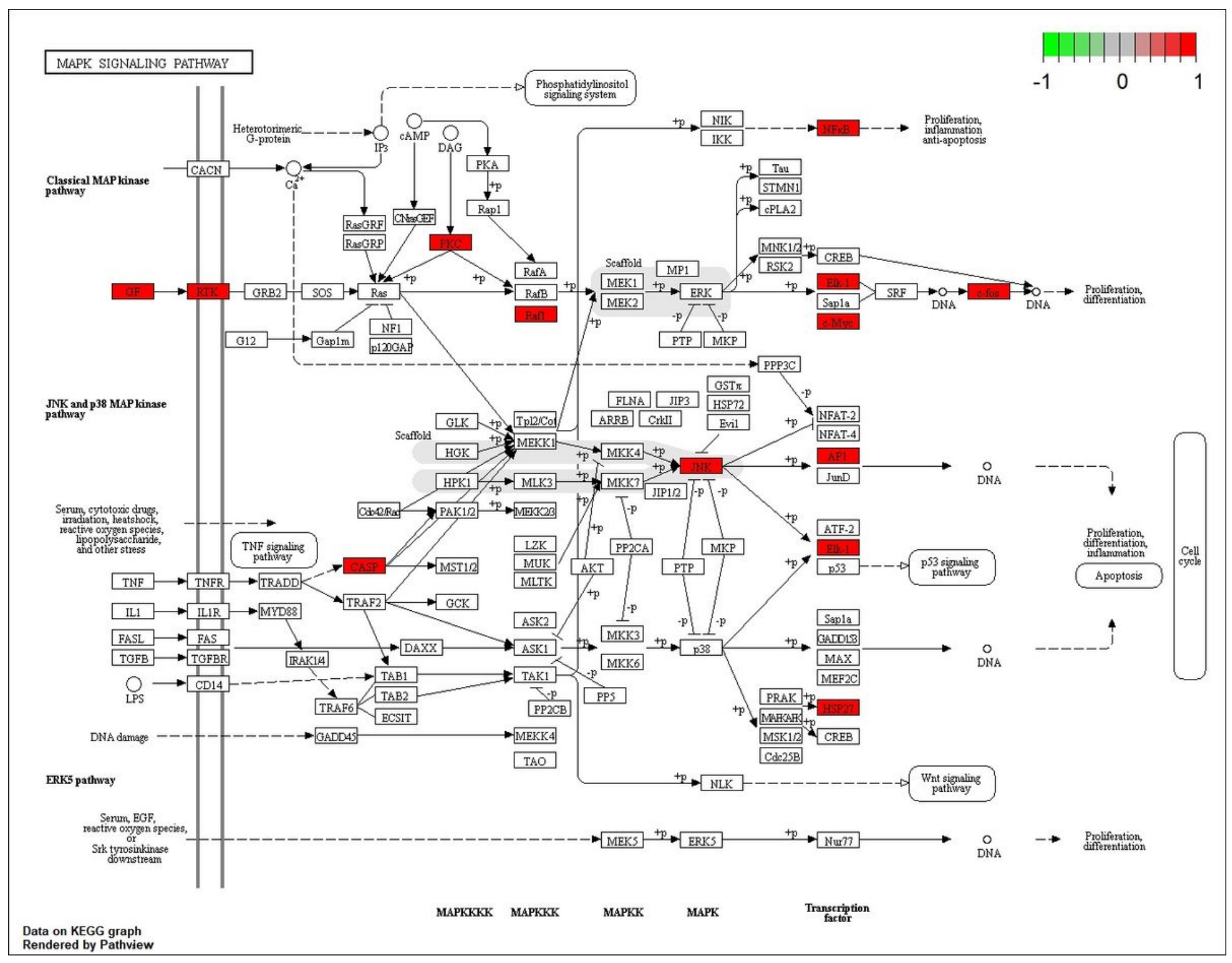

\section{Figure 5}

Target of Astragali Radix in DN pathway. The pathway map of Astragali Radix for treatment of DN using KEGG Mapper. Those top-ranking signaling pathways from KEGG analysis were integrated and mapped to obtain the final path map. 


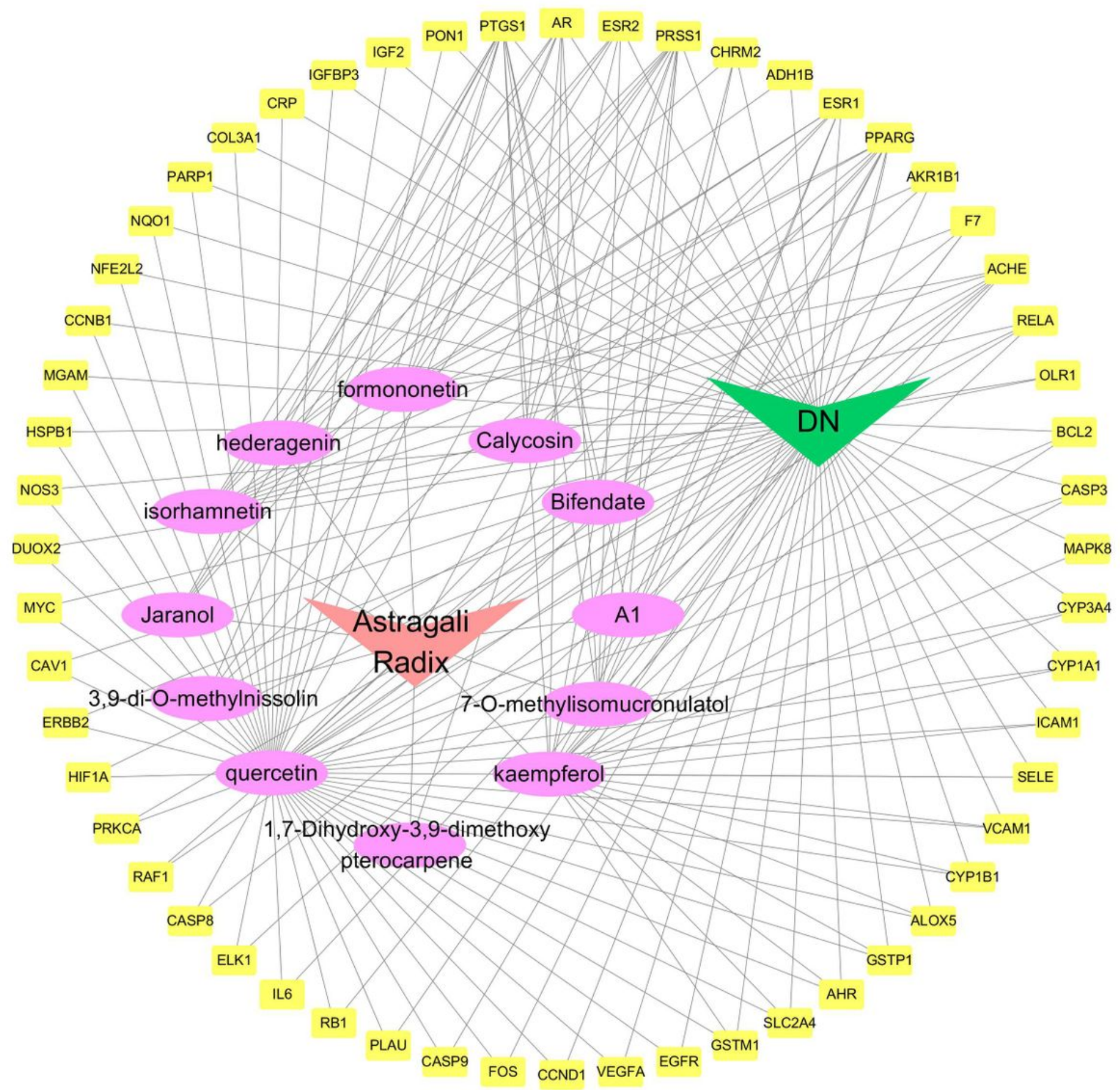

Figure 6

Drug-ingredients-targets-diseases network of Astragali Radix for treatment of DN. Cytoscape 3.6.1 was chosen to draw the drug-ingredients-target-disease network. The drug, diseases, ingredients and targets respectively used Vshaped, V-shaped, elliptical and rectangular nodes, and the relationship was represented by edges. 
A<smiles>O=c1c(O)c(-c2ccc(O)c(O)c2)oc2cc(O)cc(O)c12</smiles>

C

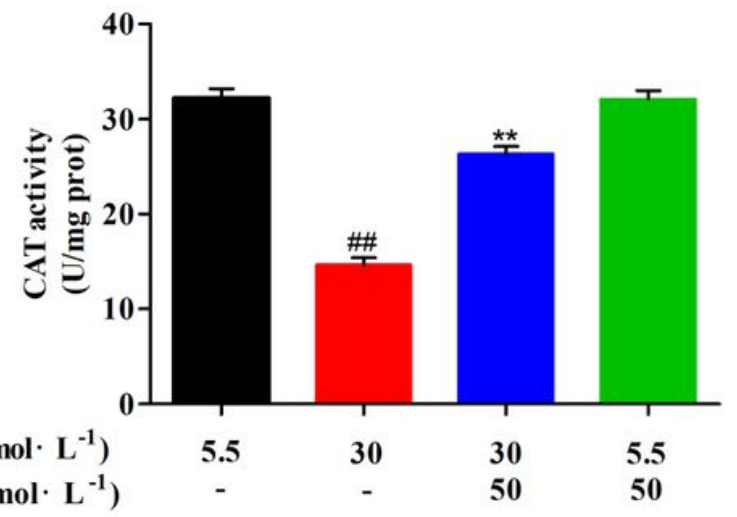

\section{Glucose $\left(\mathrm{mmol} \cdot \mathbf{L}^{-1}\right)$} Quercetin $\left(\mu \mathrm{mol} \cdot \mathrm{L}^{-1}\right)$
B

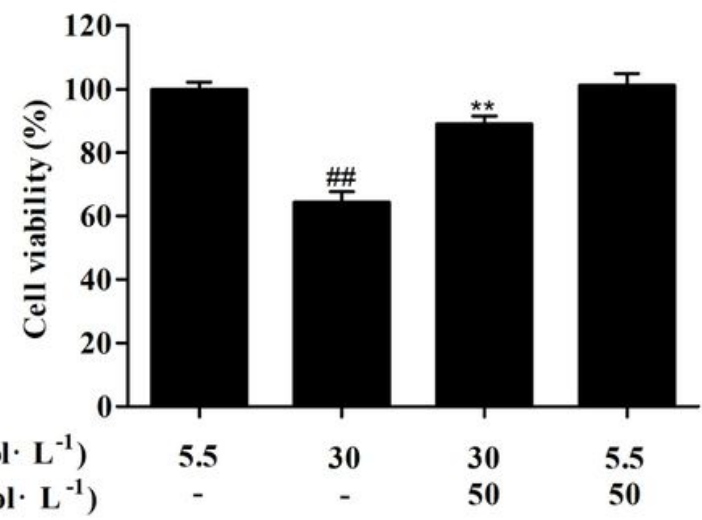

D

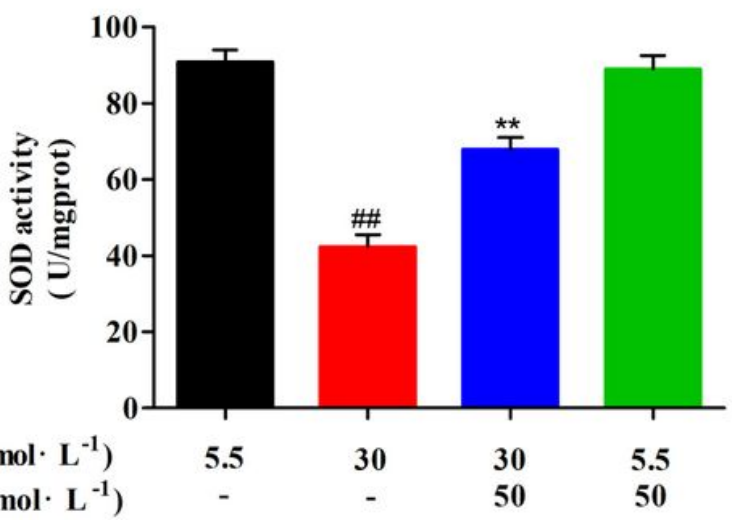

\section{Figure 7}

Glucose (mmol· $\left.\mathbf{L}^{-1}\right)$ Quercetin $\left(\mu \mathrm{mol} \cdot \mathbf{L}^{-1}\right)$

Effects of quercetin on the cytotoxicity and antioxidant capacity in high glucose-induced HK-2 cells. (A) Chemical structure of quercetin. Its molecular weight is 302.25 . (B) HK-2 cells were divided into control group $(5.5 \mathrm{mmol} \cdot \mathrm{L}-1$ glucose), high glucose group (30 $\mathrm{mmol} \cdot \mathrm{L}-1)$, high glucose $(30 \mathrm{mmol} \cdot \mathrm{L}-1)+50 \mu \mathrm{mol} \cdot \mathrm{L}-1$ quercetin group and quercetin group ( $5.5 \mathrm{mmol} \cdot \mathrm{L}-1$ glucose $+50 \mu \mathrm{mol} \cdot \mathrm{L}-1$ quercetin) for $24 \mathrm{~h}$. Cell viability was measured by a CCK-8 assay. (C-D) HK-2 cells were treated with high glucose $(30 \mathrm{mmol} \cdot \mathrm{L}-1)$ and quercetin $(50 \mu \mathrm{mol} \cdot \mathrm{L}-1)$ in 6 -well plates for $24 \mathrm{~h}$. Effects of quercetin on CAT and SOD activities. Values were expressed as mean $\pm S D(n=6)$. \#\#P<0.01 vs control group, ${ }^{* *} \mathrm{P}<0.01$ vs high glucose group. 
A

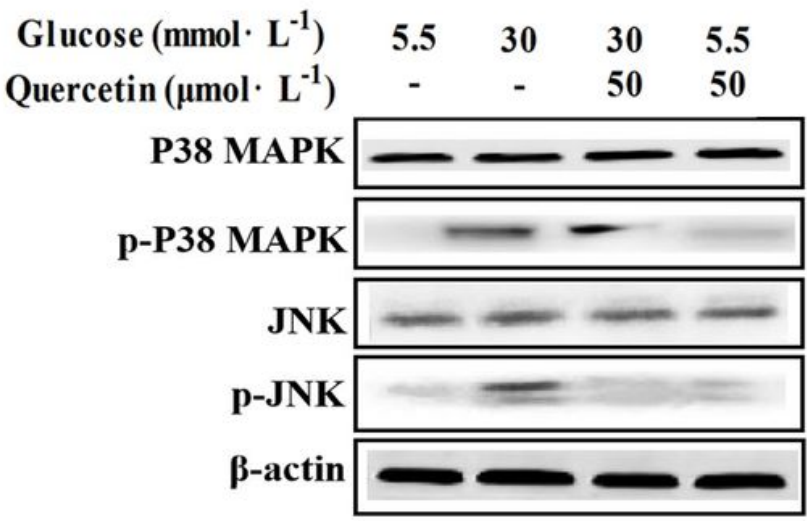

B

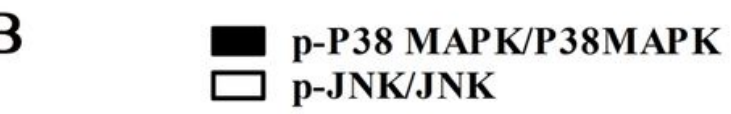

Figure 8

Quercetin suppressed MAPK signaling pathway in high glucose-induced HK-2 cells. HK-2 cells were treated with high glucose $(30 \mathrm{mmol} \cdot \mathrm{L}-1)$ and quercetin $(50 \mu \mathrm{mol} \cdot \mathrm{L}-1)$ in 6-well plates for $24 \mathrm{~h}$. (A) The protein expressions of P38 MAPK, JNK, phospho-P38 MAPK and phospho-JNK were measured by Western blotting. (B) Quantification and statistical analysis of MAPK activation. Values were expressed as mean $\pm S D(n=3)$. \#\#P<0.01 vs control group, ${ }^{\star *} \mathrm{P}<0.01$ vs high glucose group. 